\title{
The distribution of plasminogen activator in the male genital tract
}

\author{
R. C. KESTER \\ From the Department of Surgery, Dundee Royal Infirmary
}

SYNOPSIS The distribution of fibrinolytic activity in the tissues of the male genital tract was studiec by a histological technique. Preparations made from testis, epididymis, vas deferens, semina $F$ vesicle, prostate, bulbo-urethral gland, and urethra showed that most activity was related to the blood vessels. However, inconsistent fibrinolytic activity related to epithelium was found in alf parts of the genital tract. This epithelial activity was least in the testis, greater in the seminal vesicle? and prostate gland, and was greatest in the bulbo-urethral gland and terminal urethra. No fibrinolytic activity could be demonstrated in relation to spermatozoa.

The cycle of coagulation and liquefaction of semen resembles the clotting and fibrinolysis of blood. Fibrinolytic activity appears in the blood when a pro-enzyme, plasminogen, is converted to the active protease, plasmin, by an 'activator'. This protease then digests fibrin. Similarly, when seminal fluid is ejaculated, it coagulates immediately and is then reliquefied within about 20 minutes by proteolytic activity. Human semen contains a fibrinolytic substance which Huggins and Neal (1942) thought was a protease of prostatic origin, but it was later shown that the substance was in fact an activator of the plasminogen system (von Kaulla and Shettles, 1953).

Using the histological technique of 'fibrinolysis autography' (Todd, 1959), which reveals the topography of plasminogen activator in tissues, it has been shown that activator is concentrated not only in the vascular endothelium of the prostate, but also to a lesser degree in the epithelium of the glands and ducts (Kester, 1969). In the latter studies, the amount of activator demonstrable in the prostatic epithelium seemed insufficient to be the only source of the fibrinolytic activity of human seminal fluid. In an attempt to find the source of plasminogen activator in seminal fluid, the other tissues of the genital tract have now been examined by fibrinolysis autography.

\section{Materials and Method}

Tissues were taken from the reproductive organs of 14 adult males at routine necropsies within 24 hours of death (see Table I for clinical details). Blocks from Received for publication 10 March 1971.

\begin{tabular}{|c|c|c|c|}
\hline Case No. & Age (yr) & Cause of Death & \\
\hline 1 & 68 & Chronic lymphatic leukaemia & \\
\hline 2 & 55 & Cancer of caecum & \\
\hline 3 & 46 & Cerebral haemorrhage & \\
\hline 4 & 58 & Cancer of colon & 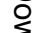 \\
\hline 5 & 82 & Cardiac failure & \\
\hline 6 & 77 & Cancer of pancreas & \\
\hline 7 & 44 & Muscular dystrophy & \\
\hline 8 & 60 & Cerebral infarction & \\
\hline 9 & 22 & Multiple injuries & 2 \\
\hline 10 & 44 & Myocardial infarction & \\
\hline 11 & 63 & Cancer of stomach & 2 \\
\hline 12 & 58 & Cardiac failure & \\
\hline 13 & 57 & Myocardial infarction & \\
\hline 14 & 61 & Cancer of stomach & \\
\hline
\end{tabular}

Table I Details of source of human tissue

testis, epididymis, vas deferens, seminal vesicle prostate, bulbo-urethral (Cowper's) gland, and urethra were each placed in a small polythene bago containing Michaelis veronal buffer saline (Biggs

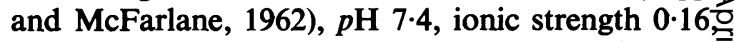
with sodium azide $0.1 \%$ as a bacteriostatic. The samples were 'quick frozen' by plunging the bags ${ }^{\circ}$ into a dry ice-acetone mixture and stored at $-30^{\circ} \mathrm{C}$ in the deep freeze. Tissue sections of about $8 \mu \mathrm{w}$ thickness were cut from the blocks on a cryostato microtome before making the histological preparations.

PLASMINOGEN-RICH FIBRINOGEN A $2 \%$ solution by weight of bovine plasma fraction I (Armour) $^{1}$ was made in veronal buffer saline $\stackrel{\overparen{D}}{\overparen{D}}$

${ }^{1}$ This preparation of bovine fibrinogen contains plasminogen as $a$ contaminant, and $40-60 \%$ by weight of sodium citrate. 
THROMBIN SOLUTION

Thrombin, topical (bovine origin) (Parke Davis): stock solution 1,000 units $/ \mathrm{ml}$ in $50 \%$ glycerol, and this was diluted to 20 units $/ \mathrm{ml}$ in Michaelis buffer saline to obtain a working solution.

\section{CELLOPHANE SHEET}

Cellophane PT 300-400 gauge (British Cellophane Ltd).

NEUTRAL BUFFERED FORMALIN SOLUTION (LILLIE, 1965)

Harris's haematoxylin (Harris, 1900).

The histochemical technique was that of fibrinolysis autography (Todd, 1964); a thin layer of bovine fibrin, rich in plasminogen, is applied to an unfixed dried section and incubated at $37^{\circ} \mathrm{C}$ (Fig. 1). Wherever the section contains activator, the plasminogen in the overlying fibrin is converted to plasmin and the fibrin is digested. When the preparation has been fixed, stained, and mounted, microscopic examination reveals the areas of digestion as pale zones in the stained fibrin background, and these can be related to structures in the overlying section.

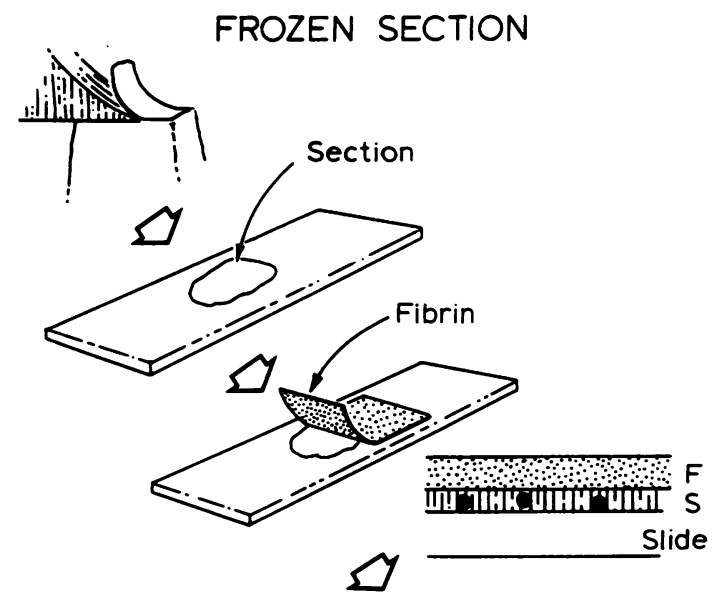

INCUBATE

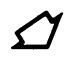

FIX and STAIN

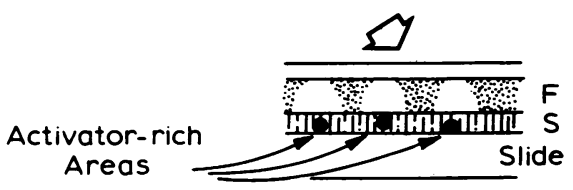

Fig. 1 The construction of a fibrinolysis autograph.
The tissue-fibrin preparations were incubated for either 15,30 , or 60 minutes, and two samples were taken at the end of each period; thus six samples were examined from each block. In each preparation the degree of fibrinolytic activity of tissue components, ie, blood vessels, glandular epithelium, and secretion, was assessed in arbitrary units, using a semi-quantitative method (Kester, 1969) based on the magnification needed to detect the zones of lysis. An average value for the fibrinolytic activity was calculated for each type of component (Table II).

\begin{tabular}{lllll}
\hline Tissue & Overall & Vascular & Epithelium & Secretion \\
\hline Testis & 13 & 13 & 1 & 0 \\
Epidydimis & 16 & 16 & 6 & 0 \\
Vas deferens & 15 & 15 & 7 & 0 \\
Seminal vesicle & 16 & 16 & 12 & 4 \\
Prostate & 16 & 16 & 11 & 3 \\
Bulbo-urethral gland & $18^{1}$ & $18^{1}$ & 14 & 6
\end{tabular}

Table II Distribution of fibrinolytic activity in the male genital tract (arbitrary units)

${ }^{1}$ Maximal activity

\section{Results}

TESTIS

The scanty blood vessels in the tunica albuginea showed little fibrinolytic activity. Zones of lysis related to the seminiferous tubules (Fig. 2) were most uncommon, and were particularly related to areas of disruption of the germinal epithelium. No fibrinolytic activity could be detected around the spermatozoa within the lumen of the tubules.

\section{EPIDIDYMIS}

Epithelial activity was infrequent, random in distribution, and of only moderate intensity (Fig. 3). Spermatozoa and secretion again seemed inactive. The blood vessels in the epididymis and the remaining accessory organs showed consistent and striking activity.

\section{VAS DEFERENS}

Scattered sites of epithelial activity of moderate intensity were seen.

SEMINAL VESICLE

The epithelial surface often exhibited striking fibrinolytic activity. Scattered within the lumen of each crypt were many disrupted cells and fragments of cellular debris; the areas of lysis were often related to these (Fig. 4). Occasionally, foci of activity seemed related only to acellular secretions. The spermatozoa again seemed inactive. 


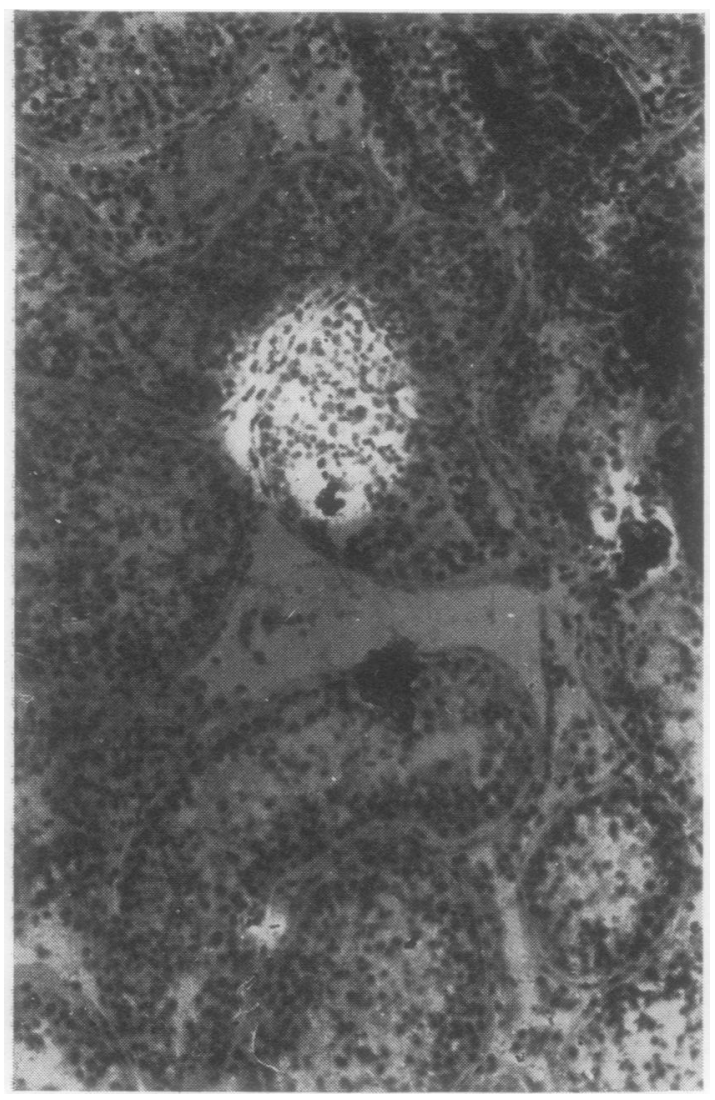

Fig. 2 Testis: fibrinolysis related to a seminiferous tubule. $60 \mathrm{~min} \times 95$.

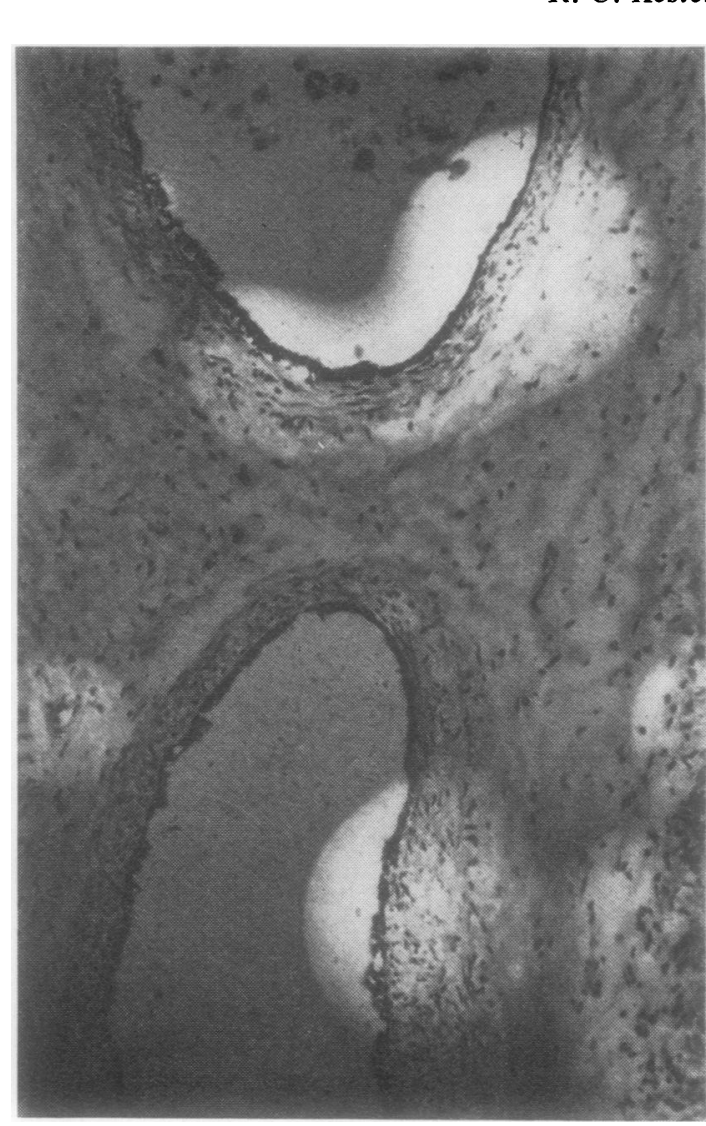

Fig. 3 Epididymis: digestion of fibrin by tubular epithelium. $60 \mathrm{~min} \times 122$.

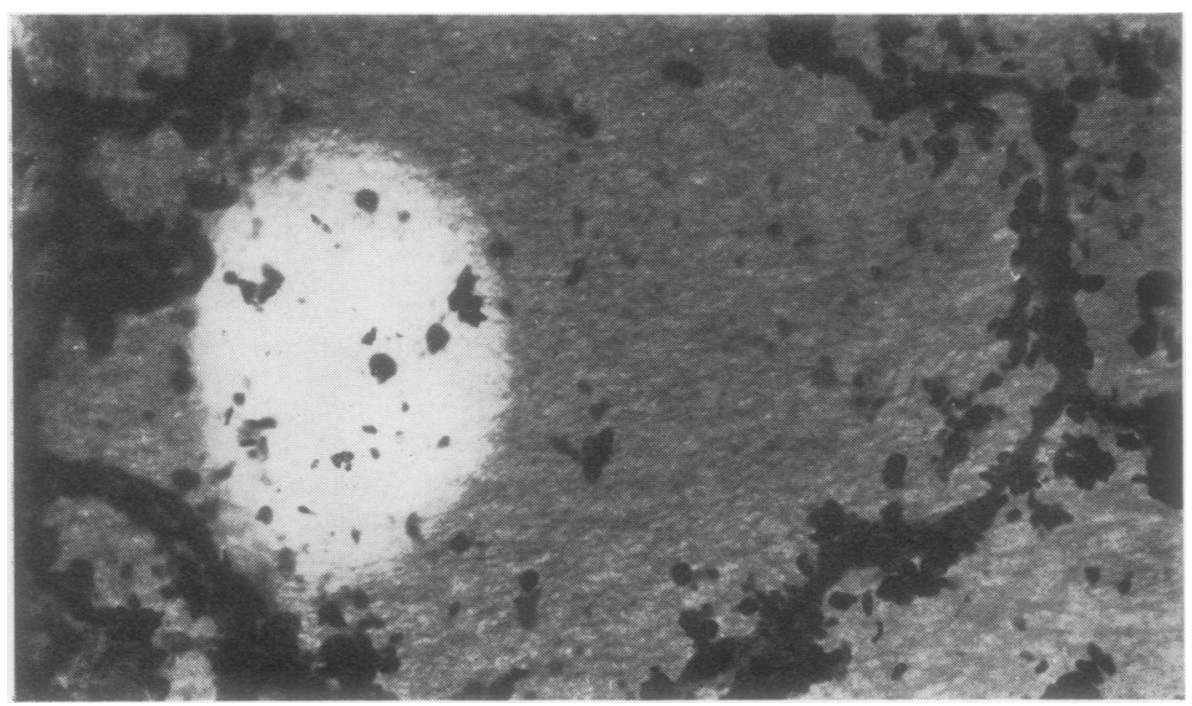

Fig. 4 Seminal vesicle: an area of digestion related to disintegrating epithelial cells. $30 \min \times 608$. 


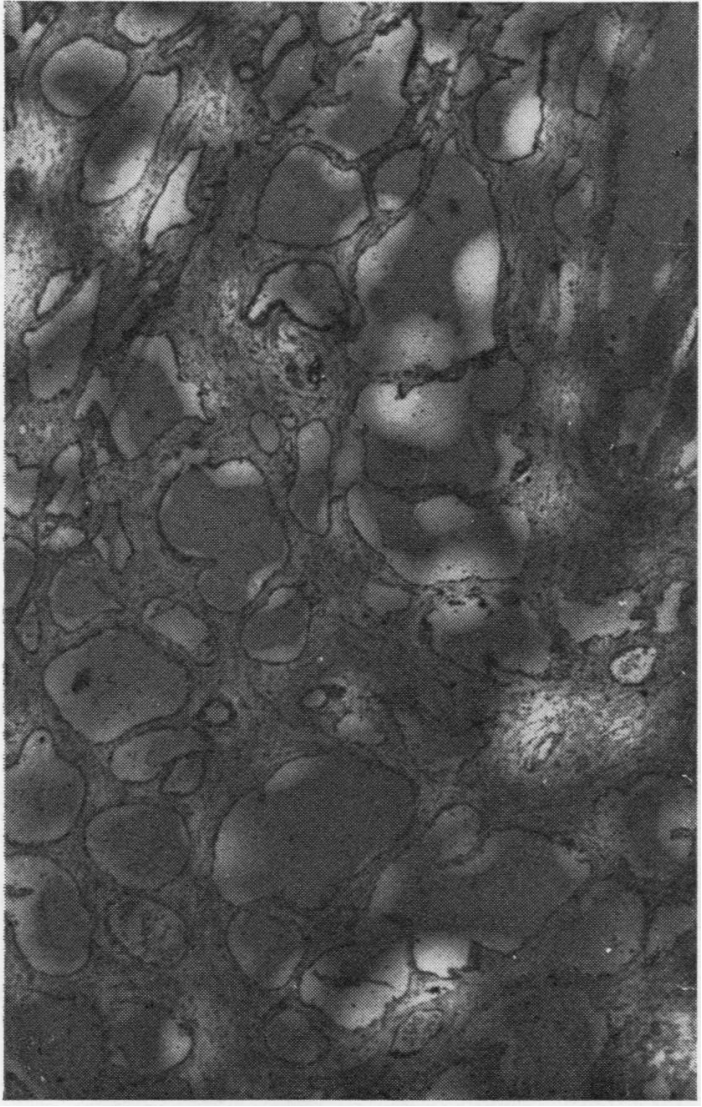

Fig. 5 Prostate: frequent zones of lysis arising from the glandular epithelium. $60 \mathrm{~min} \times 24$.

\section{PROSTATE}

Abundant zones of lysis, usually of moderate intensity, were related to the lining of the glands and ducts (Fig. 5) particularly where the epithelium was detached and presumably traumatized. Activity related to secretions was insignificant.

\section{BULBO-URETHRAL GLAND}

Of all the accessory organs, the bulbo-urethral gland showed the greatest levels of fibrinolytic activity. Figure 6 shows massive digestion of the substrate related to the glandular acini. The large ducts communicating with the urethra also exhibited conspicuous activity.

\section{URETHRA}

Figure 7 shows the vigorous fibrinolytic activity characteristic of urethral mucosa especially where there is epithelial disruption. Mild fibrinolytic

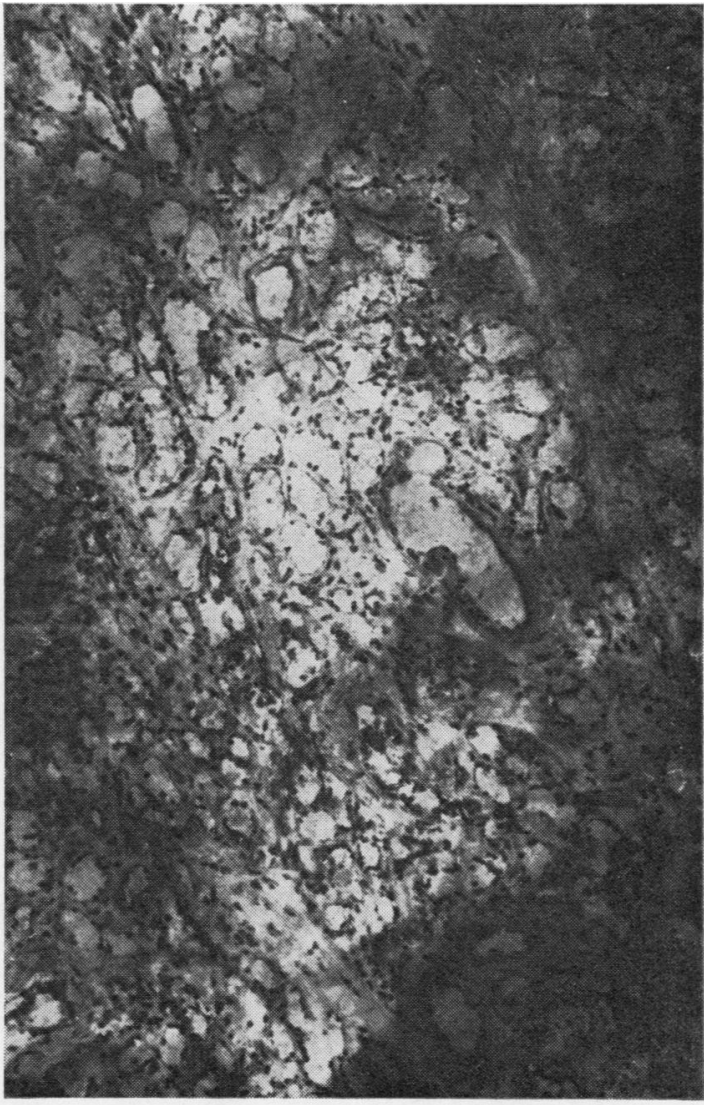

Fig. 6 Cowper's gland: lysis related to several acini. $60 \min \times 95$.

activity was related to the urethral glands of Littré (Fig. 8).

\section{Discussion}

After examining the fluid obtained by prostatic massage, Huggins and Neal (1942) presumed that the source of seminal fibrinolysin was the prostate gland. Some doubt was cast on this deduction when Harvey (1949) showed that the fibrinolytic activity of seminal plasma was independent of the proportion of the prostatic component. Ying, Day, Whitmore, and Tagnon (1956) too thought that only part of the fibrinolytic activity of semen could be ascribed to prostatic secretion, especially since such secretion crudely obtained by prostatic massage would have some contribution from vesicular and urethral secretions. Karhausen and Tagnon (1955) attributed the fibrinolytic activity of the prostate to a trypsin- 


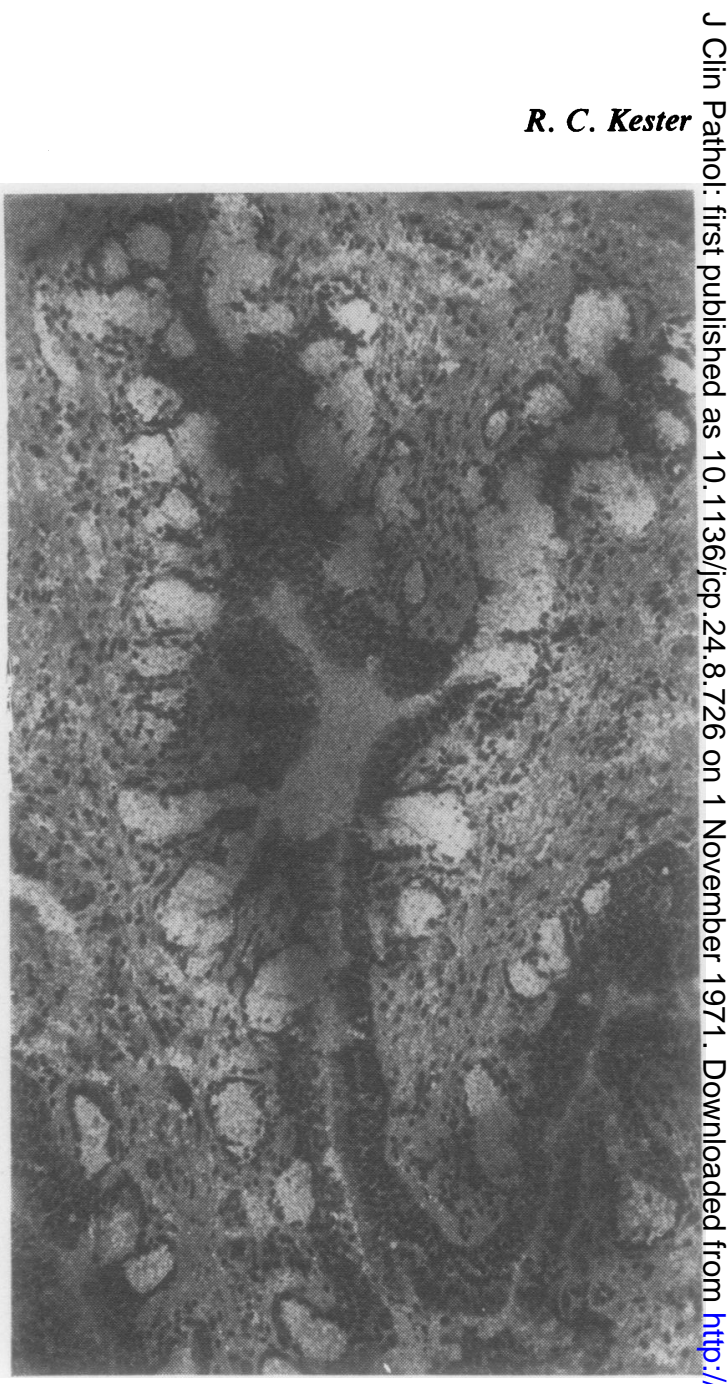

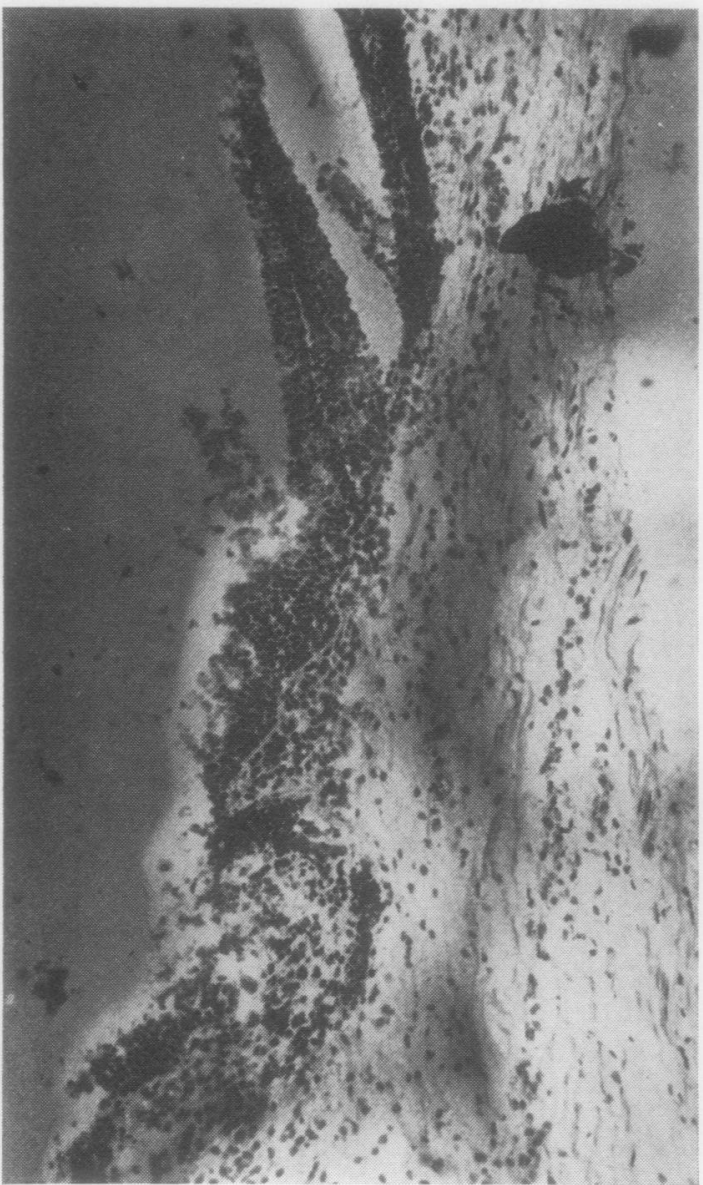

Fig. 7 Prostatic urethra: prominent activity from mucosa, especially where disrupted. $30 \mathrm{~min} \times 95$.

like protease rather than to the presence of plasminogen activator. Although the prostate is rich in plasminogeh activator (Albrechtsen, 1957; Rasmussen, Albrechtsen, and Astrup, 1958; Rasmussen and Albrechtsen, 1960), nevertheless the histological technique shows that the activator is largely confined to the vessels, making it unlikely that the prostate contributes much fibrinolytic activity to the ejaculate.

The normal secretory processes in male accessory glands are accompanied by definite changes in epithelial structure varying from desquamation to cell rupture (Mann, 1964). Analysis of the glandular fluid confirms the presence not only of whole epithelial cells but also of glandular debris. In the histological preparations, fibrinolytic activity related to such debris wasconspicuous. This observation
Fig. 8 Urethra: mild fibrinolytic activity arising from the glands of Littré. $30 \mathrm{~min} \times 95$.

is consistent with that of Pandolfi and Astrup (1967) that damage or disruption of corneal epithelium 윽

enhances the fibrinolytic activity of these cells.
It has been shown in the present studies that the glandular epithelium of the male assessory genital $\underset{\sim}{\sim}$ organs contains plasminogen activator in varying . amounts. Although the fibrinolytic activity of blood $N$ vessels is consistently high throughout the genital $\mathbb{C}^{N}$ tract (except in the testis), the fibrinolytic activityo of epithelium increases along the genital tract ando is greatest in both the epithelium and secretion of $\frac{\text { C }}{\sim}$ Cowper's gland. The full significance of the fibrin- $\stackrel{\infty}{+}$ olysis in seminal plasma is not yet clear. Since 7 fibrinolytic activity may be necessary to main- $\bar{O}$ tain the patency of the urinary tract by digesting fibrinous deposits (Astrup and Sterndorff, 1952;零 Ladehoff, 1960; Charlton, 1966), fibrinolysis may 
similarly be necessary to maintain semen in a fluid state within the genital passages (Mann, 1964). However, the high concentration of activator in the last secretion to be added to the ejaculate-that from Cowper's glands-would suggest that the fibrinolytic activity had its main effects after ejaculation by liquefying the seminal coagulum and thus facilitating the migration of spermatozoa into the uterine cavity. It is also possible that plasmin plays a part in acrosome rupture, the process of 'sperm capacitation', and in penetration of the zona pellucida.

Huggins and Neal (1942) have shown that the fibrinolytic activity of semen was in the seminal plasma rather than in the spermatozoa; this has been confirmed using centrifugation methods checked by microscopy (Kester, 1970). In the present experiment no activator was demonstrated in spermatozoa, although Tympanidis and Astrup (1968) found that human spermatozoa in vaginal smears exhibited significant fibrinolysis. It is possible that in their material the spermatozoa were coated by seminal plasma containing activator, or that they had been activated by contact with vaginal or cervical secretions.

I am deeply indebted to Dr Alastair S. Todd for his continued interest and support, and to Mrs Anne Nunn for technical advice. I wish to thank Professor D. M. Douglas for laboratory facilities, Miss Mary Benstead, medical artist, for her assistance, $\mathrm{Mr}$ Tom King for his invaluable help in preparing the photomicrographs, and Miss Joyce Devlin for typing the script. I am grateful to the Board of Management, Dundee General Teaching Hospitals, for a research grant.
References

Albrechtsen, O. K. (1957). The fijrinolytic activity of human tissues. Brit. J. Haemat., 3, 284-291.

Astrup, T., and Sterndorf, I. (1952). An activator of plasminogen in normal urine. Proc. Soc. exp. Biol. (N.Y.), 81, 675-678.

Biggs, R., and Macfarlane, R. G. (1962). Human Blood Coagulation and its Disorders, 3rd ed., p. 370. Blackwell, Oxford.

Charlton, C. A. C. (1966). Pathogenesis of urolithiasis: relation of urinary fibrinolytic activity to nondialyzable urinary solids. Surg. Forum, 17, 503-505.

Harris, H. F. (1900). On the rapid conversion of haematoxylin into haematein in staining, reactions. J. appl. Micro., 3, 777-780.

Harvey, C. (1949). Fibrinolysin in human semen. A method of assay, and some preliminary observations. Proc. Soc. Study. Fert. (Edinb.), 1, 11-17.

Huggins, C., and Neal, W. (1942). Coagulation and liquefaction of semen. Proteolytic enzymes and citrate in prostatic fluid. $J$. exp. Med., 76, 527-541.

Karhausen, L., and Tagnon, H. (1955). Le syndrome de fibrinolyse prostatique: nature de l'activité protéolytique de la prostate. Acta clin. belg., 10, 471-476.

von. Kaulla, K. N., and Shettles, L. B. (1953). Relationship between human seminal fluid and the fibrinolytic system. Proc. Soc. Exp. Biol. (N.Y.), 83, 692-694.

Kester, R. C. (1969). Plasminogen activator in the human prostate. J. clin. Path., 22, 442-446.

Kester, R. C. (1970). The Distribution of Plasminogen Activator in the Male Genital Tract. ChM Thesis, University of Cape Town.

Ladehoff, A. (1960). The content of plasminogen activator in the human urinary tract. Scand. J. clin. Lab. Invest., 12, 136-139.

Lillie, R. D. (1965). Histopathologie Technic and Practical Histochemistry, 3rd ed., p. 38. McGraw Hill, New York.

Mann, T. (1964). The Biochemistry of Semen and of the Male Reproductive Tract, 2nd ed. Methuen, London.

Pandolf, M., and Astrup, T. (1967). A histochemical study of the fibrinolytic activity: cornea, conjunctiva, and lacrimal gland. Arch. Ophthal., 77, 258-264.

Rasmussen, J., and Albrechtsen, O. K. (1960). Characterisation of the fibrinolytic components in the human prostate. Scand. J. clin. Lab. Invest., 12, 261-268.

Rasmussen, J., Albrechtsen, O. K., and Astrup, T. (1958). The fibrinolytic activity in the human prostate and in seminal fluid. Proceedings 6th Congress of the European Society of Haematology, vol. 2, p. 494. Karger, Basle.

Todd, A. S. (1959). The histological localisation of fibrinclysin activator. J. Path. Bact., 78, 281-283.

Todd, A. S. (1964). Localization of fibrinolytic activity in tissues. Erit. med. Bull., 20, 210-212.

Tympanidis, K., and Astrup, T. (1968). Fibrinolytic activity of rat, rabbit and human sperm cells. Proc. Soc. exp. Biol. (N.Y.), 129, 179-182.

Ying, S. H., Day, E., Whitmore, W. F., and Tagnon, H. J. (1956). Fibrinolytic activity in human prostatic fluid and semen. Fertil. and Steril., 7, 80-87. 